\title{
Mecânica e educação para o trânsito: análise de um texto didático de ciências para o ensino fundamental
}

\author{
Mechanics and traffic education: analysis of a didactic science text to elementary school \\ Maria Cristina do Amaral Moreira ${ }^{1}$, Marcus Vinicius Pereira*1, Isabel Gomes Martins ${ }^{2}$ \\ ${ }^{1}$ Instituto Federal de Educação, Ciência e Tecnologia do Rio de Janeiro, Rio de Janeiro, RJ, Brasil \\ ${ }^{2}$ Universidade Federal do Rio de Janeiro, Rio de Janeiro, RJ, Brasil
}

Recebido em 18 de Novembro, 2016. Revisado em 2 de Abril, 2017. Aceito em 12 de Abril, 2017.

\begin{abstract}
Neste artigo analisamos um texto sobre educação para o trânsito de um livro didático de ciências do ensino fundamental autorado por pesquisadores e aprovado pelo PNLD, na sua relação com os aportes teóricos da Ciência-Tecnologia-Sociedade (CTS) com base na análise crítica do discurso. Os resultados apontaram estratégias discursivas que recontextualizam, sobretudo, o conceito de velocidade com questões socioambientais das grandes cidades implicando os estudantes pela reflexão dos riscos (nível individual e coletivo) exposição de posicionamentos e problematização de ações cotidianas envolvendo deslocamento de pessoas e veículos (segurança no trânsito, tecnologia dos automóveis, acidentes).
\end{abstract}

Palavras-chave: livro didático, análise crítica do discurso, ciência-tecnologia-sociedade.

In this article we analyze a text about traffic education from a science textbook of elementary school written by researchers and approved by the Brazilian Science Textbook Evaluation Program, in its relationship with the theoretical contributions of Science-Technology-Society (STS) based on critical discourse analysis The results point discursive strategies recontextualized mainly the concept of velocity, comprising environmental issues of major cities in the involvement of students through, risk reflection (individual and collective), exposure placements and the problems found by everyday actions involving movement of people and vehicles (traffic safety, automobile technology, accidents).

Keywords: textbook, critical discourse analysis, science-technology-society

\section{Introdução}

O ensino de ciências na sociedade atual deve implicar valores e ética na relação com questões sociocientíficas de modo, pelo menos em parte, a escapar de uma educação alienante [1]. Expressões tais como educar para a cidadania, para a transformação e para a emancipação social são proclamadas em direção a uma educação científica reflexiva em documentos contendo orientações curriculares, diretrizes para a formação docente e discente, bem como pesquisas vinculadas à perspectiva da Alfabetização Científica e às abordagens Ciência-TecnologiaSociedade (CTS). Essa influência se estende também ao livro didático (LD) de ciências, material empírico desta investigação. Por exemplo, o PNLD 2010 para os primeiros anos do Ensino Fundamental [2] relaciona de forma notória a melhoria do LD como resposta às críticas feitas ao ensino de ciências que, por tratar de

temas e práticas descontextualizadas, muito distantes da realidade e do dia-a-dia dos alunos, têm dificultado a compreensão de como a ciência e a tecnologia são produzidas e

*Endereço de correspondência: marcus.pereira@ifrj.edu.br afetam nossa sociedade. O livro didático de ciências deve contribuir para romper com este modelo ineficiente e familiarizar o estudante com a pesquisa, destacando o prazer e a utilidade da descoberta, contribuindo para a formação de cidadãos aptos a responder aos questionamentos que o século XXI nos coloca [2] (grifos nossos)

O edital do PNLD 2014 direcionado ao ensino de ciências do segundo segmento $\left(6^{\circ}\right.$ ao $9^{\circ}$ ano $)$ do Ensino Fundamental [3] solicita a contextualização de conteúdos, remetendo à formação para a cidadania o estabelecimento de relações entre ciência, tecnologia e práticas cotidianas dos alunos por meio de sua aproximação com a realidade A contextualização é um termo caro para os pesquisadores no sentido que tem para a formação da cidadania, implicada com "a necessidade da reflexão crítica e interativa sobre situações reais e existenciais para os estudantes" [4]. Para que não se transformem em clichês, faz-se necessária "a explicitação clara de seu significado para evitar interpretações ingênuas" [5].

Considerando os argumentos apresentados, buscamos entender os discursos relacionados à linha de pesquisa 
CTS em interseção com o discurso da ciência escolar no LD de ciências por meio da análise de um texto sobre educação para o trânsito de um LD autorado por pesquisadores, problematizando a ideia de que esse recurso não traz as discussões centrais sobre as principais relações apontadas pelas abordagens CTS [6]. Devido à centralidade do LD na prática pedagógica, entende-se que ele constitui espaço potencialmente transformador do discurso escolar, mesmo que as mudanças estejam condicionadas por recomendações oficiais, pedagógicas e/ou científicas. Dessa forma, buscou-se por discursos que representam a contraposição da lógica hegemônica imposta pela colonização do mercado editorial nos textos didáticos, ou seja, por nichos de mudança discursiva no LD.

\section{Embasamento teórico-metodológico}

Nossa investigação se fundamenta na Análise Crítica do Discurso (ACD) de Fairclough [7, 8], que considera textos como ações no mundo que respaldam, aprofundam, negligenciam e reformulam essas mesmas ações. Assim, o LD, não sendo apenas uma produção textual, espelha um modo de atuação sociodiscursiva em uma cultura [9]. O discurso é entendido como momento da prática social de ensinar ciências, e permite, por exemplo, compreender processos culturais, históricos e conceituais envolvendo as perspectivas CTS os aspectos epistemológicos e filosóficos, atrelados ao funcionamento da linguagem pelas suas representações no discurso [10].

Quando analisamos o discurso CTS recontextualizado no LD, consideramos uma demanda para sua incorporação no livro, porém é a análise textual que revelará a presença ou ausência desse discurso. A presença do discurso CTS pode ser significada em vários níveis na perspectiva da ACD: os discursos associados às perspectivas CTS, o significado dessa associação, os elementos destacados e silenciados, entre outros. A configuração final pode apresentar um discurso CTS mais voltado às recomendações oficiais, às pesquisas da área de EC, às necessidades da prática pedagógica ou à vida cotidiana das pessoas, de forma isolada, ou mesmo em uma convergência particular.

A análise envolve duas etapas mutuamente dependentes: (i) conjuntura, reflexão acerca da história, pressupostos e orientações da linha de pesquisa CTS, bem como das recomendações oficiais, objetivos e finalidades do ensino de ciências; (ii) microanálise, análises de textos que circulam nas práticas sociais em estudo. Para tal, buscamos identificar e significar essas relações por intermédio das escolhas lexicais, transitividade, de estilo e modo retórico das representações discursivas no texto.

\section{A linha de pesquisa e a educação Ciência-Tecnologia-Sociedade}

Linhas de pesquisa podem ser consideradas como "conjunto de pesquisas com focos de interesse específicos, representadas por um número de questões, sobre determinado enquadramento teórico e metodológico, produzindo conhecimento próprio de uma comunidade de estudo" [11]. Há inúmeros aspectos envolvidos na educação CTS, e, nesse trabalho, procuramos dialogar com conceitos tais como a inclusão de temas sociais nas ciências naturais, a ciência como atividade humana, a tomada de decisões e a formação para cidadania. A educação CTS entende que as ações curriculares (plano de aula, estratégias e materiais de ensino etc.) devem auxiliar na compreensão das implicações da ciência e da tecnologia nos modos de produção social [12]. Nesse sentido, considera-se relevante trabalhar a ciência como atividade humana, historicamente contextualizada, incluindo cenários socioeconômicos e culturais em articulação com a tecnologia e a sociedade [13] A escola socializa formas específicas de pensar e crer a ciência, desde as que privilegiam o endereçamento do conhecimento a uma elite social àquelas que valorizam o papel do conhecimento científico na formação humanista e crítica do cidadão [14]. Para a ACD, essas opções estão associadas a visões de mundo que lutam por uma hegemonia no âmbito do discurso científico-escolar.

A perspectiva CTS opõe-se a visões universalistas ao defender o conhecimento escolarizado em articulação com os saberes da população não acadêmica, em uma concepção de ciência não exclusiva de um público restrito. As diferentes matrizes de racionalidade (científica, tecnológica, social, cultural), inseparáveis no cotidiano, podem estar mais presentes em abordagens de ensino alinhadas aos pressupostos CTS [15]. De acordo com a $\mathrm{ACD}$, esse exemplo contribui no aprofundamento da reflexividade, fundamental às sociedades contemporâneas, ao expor a ideologia por intermédio da fragmentação e resistência às ideias naturalizadas. Um ensino de ciências que desnaturalize certas formas de ensinar possibilita reflexividade e contribui para a construção de identidades diversas, oferecendo um diálogo mais democrático às sociedades atuais.

\section{O ensino de física e a educação para o trânsito}

A educação para o trânsito é um tema de abordagem transversal nos currículos da educação básica, e, na física, ganha destaque no ensino da mecânica, tanto nos tópicos de cinemática quanto nos de dinâmica, ao mesmo tempo em que permite, por exemplo, uma educação CTS. Pensar o trânsito em grandes centros urbanos é um relevante problema para a sociedade, almejando a formação de motoristas e pedestres mais conscientes. Se por um lado a abordagem desse tema é importante, por outro isso não se reflete de forma tão contundente na literatura da área de ensino. Ledur [16] identificou 15 trabalhos (artigos, dissertações e teses) voltados à conscientização, sensibilização e adoção de melhores atitudes, conjugados ou não com a aprendizagem das leis e normas de trânsito, 
em que apenas cinco relacionavam a educação para o trânsito e o ensino de física, sendo quatro nos últimos 15 anos, em que

os conceitos de Física estão vinculados a situações de trânsito com enfoque principal para o desenvolvimento de conteúdos conceituais. [...] é sugerida uma proposta curricular para a inserção do tema nessa disciplina. [...] é apresentada uma proposta de unidade didática abordando velocidade, atrito, distância de frenagem e colisões. (p.25)

Silva [17] ressalta que a educação para o trânsito tem respaldo no Código de Trânsito Brasileiro (CTB) lei $\mathrm{n}^{\circ}$ 9.503 de 23 de setembro de 1997, sendo um direito de todo cidadão. Apesar do artigo 74 dessa lei explicitar que a educação para o trânsito deve ser promovida desde os anos iniciais do ensino fundamental com ações coordenadas entre todas as esferas de governo, praticamente não existem iniciativas de sua inserção no ensino básico, e as "justificativas para esta constatação talvez possam ser a não percepção pela sociedade e pelos educadores dos problemas oriundos do trânsito e/ou a falta de materiais didáticos disponíveis para a educação para o trânsito" (p.3). Em se tratando do LD, constata-se pouca expressividade. Por exemplo, Silva [17] identificou apenas o texto "Viajando em segurança na companhia de Newton" em um livro de física, em que a perspectiva da educação para o trânsito estava apenas no título.

\section{Corpus da pesquisa}

O texto selecionado localiza-se no capítulo nove, intitulado Viajando com Segurança, da unidade quatro do volume quatro da coleção Construindo Consciências [18 $]^{1}$. direcionado ao nono ano do ensino fundamental, tradicionalmente voltado ao ensino das ciências físicas e químicas. Esse capítulo foi indicado, em entrevista, por um dos autores do LD como exemplo de texto que inclui discursos relacionados à linha de pesquisa CTS. O texto pode ser caracterizado como o de introdução do capítulo, e trata de problemas e necessidade de segurança, relacionados à velocidade de veículos que trafegam em centros urbanos hoje.

A unidade do livro denominada "Ciência, Tecnologia e Sobrevivência" na qual o capítulo está inserido é composta por três capítulos (7, 8 e 9$)$. O título da unidade faz alusão ao acrônimo CTS, atribuindo significado diferente para a última letra, vinculando sociedade-sobrevivência como uma necessidade do cidadão atual de relacionar elementos da ciência e da tecnologia com questões envolvendo riscos e qualidade de vida. Há na palavra sobrevivência um sentido negativo/pejorativo, equivalente a algo de menor valor do que viver, suscitando a discussão

\footnotetext{
1 No guia do PNLD de 2014 o livro didático em questão é chamado de Projeto Velar-Ciências. Disponível em: <http://www.fnde.gov.br/programas/livro-didatico/guia-dolivro/guia-pnld-2014>.
}

da forma como muitas pessoas vivem atualmente, ou seja, apenas sobrevivem, além da discussão de temas como riscos e sustentabilidade, modos de organização etc.

O primeiro capítulo da unidade, intitulado Estratégias de Defesa dos Organismos, faz uso da metáfora dos mecanismos da evolução biológica para dimensionar a capacidade de sobrevivência dos seres vivos, nas formas de proteção desenvolvidas por eles ao longo do tempo. A questão da proteção parece estar organizada de forma a servir de base à posterior problematização da necessidade de segurança, no contexto de potenciais riscos e danos causados por aparatos tecnológico-científicos produzidos pela sociedade. O capítulo oito, Tecnologia $e$ Saúde, vincula esses termos ao propor discussões sobre aplicação/produção de vacinas e antibióticos pelos laboratórios farmacêuticos, proliferação de aparelhos de alta definição para diagnósticos de doenças, uso de técnicas de transplantes e de próteses e tecnologias de transformação como a produção de transgênicos, clones e células- tronco. Por fim, o capítulo Viajando com Segurança, objeto de análise deste artigo, inclui o debate de procedimentos de segurança no trânsito no contexto da aprendizagem de mecânica e na sua relação com a qualidade de vida das pessoas.

\section{Análise}

O cabeçalho do capítulo nove é composto por três elementos: o título do capítulo propriamente dito (Viajando com Segurança), um enunciado de trinta e cinco palavras e um conjunto de três imagens. O texto se inicia na primeira página do capítulo, no qual se encontram os elementos supracitados, e segue até a metade da página seguinte. Outros elementos semióticos estão presentes na segunda página: um quadro de estatísticas de acidentes de trânsito retirado de um site governamental e uma imagem à direita do texto e do quadro sob a forma de desenho de um homem dirigindo um automóvel e fazendo uso do cinto de segurança. Dessa forma, dividimos a análise em três subseções: do título e de elementos introdutórios, do texto em si e da relação com a linha de pesquisa CTS.

\subsection{Título e elementos introdutórios}

O título Viajando com Segurança faz uso do gerúndio como tempo verbal que produz o efeito de uma ação presente, contínua e conjunta. O emprego do verbo no gerúndio é recorrente, inclusive no título da obra, caracterizando um estilo discursivd ${ }^{2}$ de autoria, que marca o comprometimento dos autores com o envolvimento do leitor/estudante. Parece também contribuir para aproximar

\footnotetext{
$\overline{2}$ Estilos discursivos estão relacionados às formas como as relações sociais e identidades sociais são manifestadas e construídas nos discursos. Uma das formas de entender esses estilos se dá pela categoria analítica da modalidade, que permite entender processos de identificação no comprometimento do falante, escritor, produtor em suas proposições, tanto na forma que se identifica, como por aquela que outros o identificam [10].
} 
a perspectiva CTS no discurso dessa coleção didática no sentido da implicação do sujeito com aquilo que lê.

Outro componente do cabeçalho do capítulo é um enunciado de 35 palavras com informações sobre a relação entre o aumento de velocidade, o número de acidentes e os mecanismos de segurança, que servem de base para uma pergunta, antecipando a centralidade da ciência na discussão trazida no texto

Ao aumentar a velocidade com que se deslocam, os seres humanos precisam criar mecanismos de segurança para evitar acidentes. Como a ciência pode nos ajudar a compreender os dispositivos e procedimentos de segurança no trânsito? (p.184).

Para entender os enunciados representados acima, exploramos a categoria da transitividade, isto é, analisamos as sentenças como descrevendo processo $\$^{3}$, expressos por meio de verbos e envolvendo (ou não) participantes. O texto começa com o verbo transitivo direto aumentar no sentido de intensificar, provocar um aumento. Nesse exemplo, a transitividade implica os seres humanos como aqueles que usam/usarão equipamentos que empregam velocidades superiores às alcançadas pelo homem quando desprovido desses. A ênfase na agência do ser humano não corresponde à necessidade de que pessoas precisam entender que na sociedade atual há compromissos e responsabilidades de diversos níveis, individuais, institucionais e corporativos [19]. De fato, o texto destaca os seres humanos e não a indústria automobilística como agentes do aumento da velocidade e, em resposta a esse agenciamento/implicação, são os seres humanos que devem criar técnicas de proteção/segurança. Outro dado diz respeito aos seres humanos, que não implicam serem os alunos explicitamente por se referirem a eles, podendo implicar especialistas, cientistas, engenheiros, entre outros técnicos envolvidos com a questão da segurança. Portanto, esse enunciado em parte aproxima o leitor quando se remete às possibilidades de uso da tecnologia, e, ao mesmo tempo, o afasta ao enfatizar que ele não toma parte na produção dessa tecnologia. No entanto, dependendo de como é usado o texto, esse pode favorecer um entendimento da questão da segurança e das possibilidades de adotar comportamentos seguros envolvendo diferentes níveis de implicação, a saber: individual, institucional e mercadológica.

A pergunta "Como a ciência pode nos ajudar a compreender os dispositivos e procedimentos de segurança no trânsito?" é formulada por meio de interrogação direta que parece requerer uma decisão/posicionamento num modelo interativo de construção discursiva, implicada pelo pronome nos, que torna o estudante/leitor alguém comprometido com questões relacionadas à segurança no trânsito. Por meio do uso do advérbio como é chamada

\footnotetext{
3 Há dois tipos principais de processos: processos relacionais nos quais um verbo marca uma relação entre os participantes e processos de ação nos quais um participante (agente) age em direção a um objetivo [9].
}

a atenção para o modo pelo qual a ciência pode ajudar na compreensão da segurança, favorecendo a inteligibilidade de determinadas questões. No entanto, observa-se um aspecto característico da transitividade que é o da nominalização - o nome ciência passa a condensar a ideia de um processo de construção de inteligibilidade tendo como consequência imediata a supressão de um conjunto de processos e dos participantes envolvidos. A nominalização, característica da linguagem científica e técnica, promove o apagamento do processo e da agência, deixando-os em segundo plano e permitindo a construção de entidades genéricas e abstratas [9].

As três imagens estão no formato de fotografias: a primeira, à direita do título, mostra dois homens, um negro e um branco, em posição de largada em uma pista de corrida; a segunda, localizada abaixo do título, contém seis carros muitos próximos durante uma corrida de fórmula 1; a terceira, ao lado da segunda e abaixo da primeira, mostra um atleta durante uma prova de ciclismo. Essas fotos evidenciam o movimento e representam atividades vinculadas aos esportes envolvendo diferentes velocidades. Em alguma medida, esse início imprime uma abordagem que convoca o aluno a se posicionar frente ao problema destacado, pensando nas questões de velocidade e segurança como reflexo de um tipo de sociedade.

\subsection{Texto}

O texto propriamente dito é composto por sete parágrafos distribuídos em duas páginas e transcritos no Quadro 1.

O primeiro parágrafo envolve uma escolha dos verbos nascer, crescer, envelhecer e morrer, tipicamente utilizados para representar as etapas do ciclo da vida, sugerindo a possibilidade de sua perda/ruptura em consequência de acidentes. A conjugação dos verbos no presente do indicativo atribui algum grau de certeza a essa sequência típica do ciclo da vida, que, na primeira pessoa do plural, implica o leitor na proposição. De forma não explícita, os acidentes mencionados no texto parecem referir-se àqueles que ocorrem em consequência do trânsito de automóveis, na relação que se estabelece com o contexto do título Viajando com Segurança, complementado pelo quadro de estatísticas de acidentes de trânsito e o desenho do motorista fazendo uso do cinto de segurança.

O próximo parágrafo apresenta os verbos ser e ter no presente durativd 4 modo frequentemente identificado em enunciados científicos, aos quais se vinculam elevados graus de certeza e confiabilidade, enunciado que compreende alta modalidade. O conhecimento físico é reconhecido pelos limites de velocidade impostos à condição humana. As informações sobre movimento e proteção e a menção ao esqueleto humano dimensionam a questão do ponto de vista biológico.

O terceiro e o quarto parágrafos têm estruturas frasais similares: ambos iniciam com adjuntos adverbiais de

\footnotetext{
4 O tempo presente do indicativo pode exprimir diversos aspectos, entre eles o de habitualidade ou frequência e o de duração não habitual, ou seja, expressando ações ou estados mais permanentes - presente durativo.
} 
Quadro 1: Texto inicial do capítulo nove do volume 4 do livro Construindo Consciências

\begin{tabular}{|c|c|}
\hline PARÁGRAFO & TEXTO \\
\hline $1^{\circ}$ & $\begin{array}{l}\text { Nascemos, crescemos, envelhecemos e morremos. Essa sequência natural da vida é interrompida, muitas vezes, } \\
\text { por mortes precoces ou traumas irresistíveis causados por acidentes. O que podemos fazer para evitar isso? }\end{array}$ \\
\hline $2^{\circ}$ & $\begin{array}{l}\text { O corpo humano é capaz de andar, correr e saltar, atingindo velocidades máximas pouco superiores a } 10 \\
\text { metros por segundo. O sistema esquelético muscular é o responsável por nossa capacidade de locomoção. O } \\
\text { esqueleto tem, ainda, a função de proteger nossos órgãos internos de colisões e impactos com outros objetos. }\end{array}$ \\
\hline $3^{\circ}$ & $\begin{array}{l}\text { Com o auxílio de máquinas, abreviamos o tempo gasto nas viagens, ampliamos nossa força e a velocidade de } \\
\text { nossos movimentos. Porém quem se move a grandes velocidades pode, consequentemente, sofrer acidentes } \\
\text { graves. Mesmo sendo muito resistentes, os ossos não conseguem proteger o organismo quando sofremos } \\
\text { impactos em altas velocidades. Alguns tipos de acidentes passam a acontecer em razão das máquinas e dos } \\
\text { ambientes que construímos e utilizamos. }\end{array}$ \\
\hline $4^{\circ}$ & $\begin{array}{l}\text { Com o rápido crescimento e concentração populacional nos grandes centros urbanos, a circulação de pessoas } \\
\text { tornou-se um problema. Segundo levantamento do Ministério da Saúde, em } 2006,123.061 \text { pessoas foram } \\
\text { internadas pelo SUS (Sistema Único de Saúde) vítimas de acidentes de trânsito, com custo estimado de R\$ } \\
118 \text { milhões. Esse custo é mais alto se considerarmos vítimas atendidas em hospitais particulares e pacientes } \\
\text { com planos de saúde. Entretanto, muito pior do que danos materiais é a dor de ter vidas interrompidas } \\
\text { bruscamente por causa desses acidentes ou, ainda, ver as marcas que eles deixam no corpo e na memória de } \\
\text { quem os sofreu. }\end{array}$ \\
\hline $5^{\circ}$ & $\begin{array}{l}\text { Mas qual seria a maior causa de acidentes no trânsito? A imprudência de condutores e pedestres? As más } \\
\text { condições das vias de transporte e dos veículos? }\end{array}$ \\
\hline $6^{\circ}$ & $\begin{array}{l}\text { Na tabela abaixo apresentamos os dados divulgados do programa Pare (Programa de Redução de Acidentes no } \\
\text { Trânsito), realizado pelo Ministério dos Transportes com o objetivo de combater acidentes de trânsito, identifi- } \\
\text { cando, por exemplo, suas principais causas (disponível em http://www.transportes.gov.br/Pare/indexpp.htm } \\
\text { Acessado em: } 20 \text { fev.2009). }\end{array}$ \\
\hline $7^{\circ}$ & $\begin{array}{l}\text { Muito está por ser feito do ponto de vista da educação das pessoas para lidar com os dispositivos tecnológicos } \\
\text { e conviver em uma sociedade que tem cada vez mais pressa. O que a ciência tem a nos dizer sobre isso? }\end{array}$ \\
\hline
\end{tabular}

modo - "com o auxílio de máquinas" e "com o rápido crescimento e concentração populacional" - deslocados do seu lugar padrão (final da frase) e antecipados na oração, que, em geral, serve para atribuir-lhe mais importância, destacando o elemento antecipado. Esses adjuntos adverbiais, embora sintaticamente semelhantes, compreendem conteúdos diferenciados e, nessa sequência, expressam condicionantes diferentes - a tecnologia de automotores e a superpopulação do planeta - apresentados sem relação aparente. O terceiro parágrafo parece trazer um aspecto positivo dessa tecnologia ao diminuir o tempo devido ao aumento da velocidade, mas a oração adversativa seguinte - "porém quem se move em grandes velocidades pode, consequentemente, sofrer acidentes graves" inverte esse sentido ao trazer os acidentes de trânsito. Nesse parágrafo, o uso da oração adversativa contrapõe um caráter positivo às consequências negativas do aumento da velocidade ao ponderar dois lados da mesma questão. O enunciado final, "alguns tipos de acidentes passam a acontecer em razão das máquinas e dos ambientes que construímos e utilizamos", tem valor conclusivo, indicando relação direta dos acidentes pelo emprego da expressão "passam a acontecer" devido às máquinas (automotores) e ambientes (cidades/concentração humana).

No quarto parágrafo, o aspecto negativo é trazido em primeiro plano, presente em todos os enunciados que aprofundam as consequências do trânsito associadas à velocidade. No trecho "a circulação das pessoas tornou-se um problema", o verbo tornar-se indica um estado em que o sujeito é afetado por algo que está fora do seu escopo de ação. Esse trecho não implica o sujeito/aluno, tomado como espectador, e as referências ao Ministério da Saúde e ao Sistema Único de Saúde (SUS) são trazidas como estratégias discursivas que visam à persuasão. $\mathrm{O}$ argumento de autoridade é usado para conferir confiabilidade, citando dados concretos de entidades de credibilidade social.

Do segundo ao quarto parágrafo é tecida uma argumentação que visa à reflexividade dos riscos que a velocidade pode causar aos seres humanos, tanto em nível individual (segundo parágrafo) como institucional (terceiro e quarto parágrafos). No entanto, a estratégia do emprego do quadro com estatísticas de acidentes com automóveis, ao invés de destacar a prevenção, parece reforçar discursos que veem mudanças no comportamento humano como solução dos problemas de acidentes de trânsito.

Na pergunta que inicia o quinto parágrafo, "Mas qual seria a maior causa de acidentes no trânsito?", a conjunção mas é um marcador discursivo que cumpre a função de mudar a sequência de um assunto, geralmente com o intuito de retomar o enunciado anterior que ficou suspenso. Parece implicar o leitor ao suscitar sua curiosidade pela informação presente no quadro estatístico, sugerindo exemplos tais como "imprudência de condutores e pedestres" e "as más condições das vias de transporte e dos veículos".

O sexto parágrafo faz referência à fonte de dados presente no quadro estatístico, seguido do enunciado composto de elementos para responder à pergunta no quinto parágrafo, configurando argumento de autoridade ao mencionar o Ministério dos Transportes e incluir um link no qual informações atualizadas podem ser obtidas.

O enunciado do sétimo parágrafo finaliza por intermédio de uma inversão temática. A ênfase é dada àquilo que está ausente, ou seja, ao que falta no contexto da discussão das 
soluções para o problema apresentado. A sentença inicia com o pronome indefinido "muito", sujeito da locução verbal subsequente "está por ser feito", e, em seguida, apesar de implicar os estudantes ao apontar a educação como uma resposta ao problema - "sociedade que tem cada vez mais pressa" -, o grau de implicação diminui. Com a última pergunta, "O que a ciência tem a nos dizer sobre isso?", o estudante é incluído pelo uso do pronome na primeira pessoa do plural nos, lançando o leitor/interlocutor (aluno) para dentro do texto, tornando-o cúmplice do que é dito.

\subsection{Relações com a perspectiva CTS}

De acordo com o exposto, podemos entender que o texto selecionado converge em vários aspectos com os referenciais da linha de pesquisa CTS: na caracterização do contexto social, na problematização do modo de produção do conhecimento e na construção da cidadania no empoderamento do sujeito nas temáticas ensinadas, aspectos fundamentais na promoção do letramento científico [20].

\subsubsection{O contexto social como modo de produção do conhecimento}

Diferente de abordagens tradicionais nas quais cabe ao aluno o estudo de conceitos de mecânica muitas vezes sem problematizá-los com questões sociais, a análise demonstrou que é possível inserir numa discussão inicial questões de cunho CTS e que podem inclusive atravessar todo o ensino da mecânica No que diz respeito aos conceitos da mecânica que podem ser problematizados, o texto aborda a velocidade, mas ao longo do capítulo outros conceitos como variação de velocidade, inércia e a relação força, massa e aceleração são apresentados, encerrando com uma discussão sobre equipamentos e medidas de segurança. No entanto, destacamos que outros conceitos também importantes estão implícitos, tais como momento linear, colisões etc., não abordados nesse livro do nono ano.

O texto traz a questão do trânsito caracterizada de forma complexa, como imposição, benefício e fator de risco na vida dos cidadãos. Entendemos que o cenário proposto aproxima três dimensões do conhecimento: a do estudante, a da ciência e a da tecnologia. A própria configuração linguística do uso de debate como estilo discursivo é uma proposta de estratégia pedagógica amplamente alinhada aos pressupostos CTS. A discussão vinculada ao social (riscos, aumento populacional, tecnologia das máquinas) e às consequências negativas de se atingir altas velocidades permite articulações que em geral estão ausentes no ensino da mecânica. Santos e Mortimer [19] entendem que disponibilizar representações que permitam ao cidadão agir, tomar decisão e compreender o que está em jogo no discurso dos especialistas é a principal proposição dos currículos com ênfase em CTS.

Para além das questões dos indivíduos como motoristas, pedestres, moradores das cidades, há aquelas em que as influências e consequências das inovações científico- tecnológicas são de cunho social e político e, portanto, entendidas como impulsionadas por motivos econômicos (por exemplo, na referência aos planos de saúde) e não por motivos democráticos, um discurso ainda não contemplado no LD de ciências [21].

\subsubsection{Construção da cidadania pela implicação do sujeito/aluno}

O texto apresenta forte apelo à implicação dos estudantes de forma a que pensem sobre as questões rotineiras com estranhamento, permitindo abalar a estrutura de confiança nos sistemas de especialistas, possibilitando requalificação e empoderamento, já que, de acordo com Giddens [22], vivemos

num sistema sem autoridades definitivas, mesmo as crenças mais acalentadas subjacentes aos sistemas especializados estão abertas à revisão, e comumente alteradas de maneira regular. O empoderamento está disponível para o leigo como parte da reflexividade da modernidade, mas muitas vezes há problemas sobre como esse empoderamento se traduz em convicções e em ação (p. 133).

Os sistemas de especialistas, as referências às estatísticas oficiais e o discurso biológico são utilizados para construir os argumentos de "autoridade" e fatos sociais relevantes (vítimas, hospitais, pacientes, plano de saúde, dor e morte) para a retórica das consequências da velocidade no trânsito. Em geral, o discurso dos especialistas limita o desenvolvimento da formação cidadã por delegar a um grupo pequeno aquilo que é bom para a maioria das pessoas, em uma linguagem esotérica já assinalada como naturalização e universalização de discursos. Nesse contexto, o empoderamento se constrói pela dissolução de consenso naturalizado, proporcionando maior reflexividade por parte do estudante ao considerar os diversos aspectos da educação para o trânsito tanto no que constitui a sua parcela individual como do âmbito das instituições, ao formular as leis, na construção de estradas de qualidade, na formação de profissionais que controlem o trânsito entre outros.

\section{Considerações finais}

Como assinalado no início do artigo, muitas articulações discursivas ainda não estão presentes no ensino de ciências tal como os pressupostos CTS, porém nossos resultados corroboram que a introdução desses pressupostos no início do capítulo de mecânica está bem direcionada. A análise mostrou intertextos da pesquisa em educação em ciências na composição do LD analisado, tais como escolhas pautadas (i) no diálogo com o estudante, (ii) na construção do conhecimento como processo situado historicamente em oposição ao conhecimento como pronto e verdadeiro, (iii) na reflexão como forma de aprendizagem. Esses aspectos configuram uma abordagem de ensino e 
aprendizagem que recontextualiza fundamentos teóricometodológicos e resultados de pesquisas que entendem a aprendizagem agenciada pelo indivíduo, na relação que ele estabelece como relevante na construção do conhecimento, o que já traz uma dimensão importante para a formação do cidadão.

Além disso, os resultados apontam que o discurso CTS no LD analisado evidenciou outros aspectos: o contexto socioeconômico da produção do conhecimento, as possibilidades de implicar e empoderar os estudantes por meio do debate sobre os riscos, níveis de responsabilidade social, convite a posicionamento, a reflexividade como forma de desnaturalizar consensos etc.. A abordagem do capítulo não se limita a uma visão disciplinar ao incluir discussões sobre legislação, lógicas de tempo e deslocamentos na sociedade atual, envolvendo também modelos físicos, por exemplo, das relações entre força e variação da quantidade de movimento. Consideramos que alguns aspectos carecem de aprofundamento como a problematização do discurso de autoridade na linguagem científica e como certas questões influenciam a gênese e aceitação das teorias científicas por estudantes.

O título da unidade do LD "Ciência, Tecnologia e Sobrevivência" traz a sociedade tangenciando a sobrevivência, aspecto interessante sob o ponto de vista dos mecanismos da evolução presentes no LD de ciências do ensino fundamental. A contextualização do conhecimento, aspecto mais relevante para a pesquisa CTS, se deu por meio da incorporação de familiaridades do público em geral (andar, correr, saltar, dirigir) ao conteúdo tradicional das ciências biológicas e físicas, o que nos permite entender o hibridismo/pluralismo dos discursos analisados no LD. A contextualização se deu tanto nos exemplos do cotidiano hibridizados no discurso, como no aprofundamento de uma questão particular relacionada à velocidade voltada à segurança no trânsito. De maneira geral, os resultados sugerem que o texto "Viajando com Segurança" recontextualiza dois aspectos fundamentais do discurso CTS: a ênfase dada aos compromissos da ciência e tecnologia e o municiamento dos estudantes com argumentos, informações e posições críticas em relação ao problema da segurança no trânsito, na vida das pessoas e na sua própria vida.

\section{Referências}

[1] I. Mészáros, A Educação Para Além do Capital (São Paulo: Boitempo Editorial, 2008), $2^{\mathrm{a}}$ ed.

[2] Brasil, Guia do Livro Didático PNLD 2010: Ciências (MEC/SEB, Brasília, 2011).

[3] Brasil, Edital PNLD 2014: Ciências (MEC/SEB, Brasília, 2014).

[4] W.L.P. Santos, Ciência \& Ensino 1(especial) (2007), disponível em http://prc.ifsp.edu.br:8081/ojs/index. php/cienciaeensino/article/view/149/120

[5] W.L.P. Santos, in: CTS e Educação Científica: Desafios, Tendências e Resultados de Pesquisas, organizado por W.L.P. Santos e D. Auler (Editora UnB, Brasília, 2011), p. 21-48.
[6] J.A.A. Díaz, A.V. Alonso e M.A.M. Mas, Revista Electrónica de Enseñanza de las Ciencias 2, 80 (2003), disponível em http://reec.uvigo.es/ volumenes/volumen2/REEC_2_2_1.pdf

[7] N. Fairclough, Discurso e Mudança Social (Universidade de Brasília, Brasília, 2001).

[8] N. Fairclough, Analysing Discourse. Textual Analysis for Social Research (Routledge, London, 2003).

[9] L.A. Marcuschi, in: Gêneros textuais. Reflexões e Ensino, organizado por A.M. Karwoski, B. Gaydeczka e K.S. Brito (Nova Fronteira, Rio de Janeiro, 2008), $3^{\text {a }}$ ed.

[10] L. Chouliaraki and N. Fairclough, Discourse in Late Modernity. Rethinking Critical Discourse Analysis (Edinburg University Press, Edinburg, 1999).

[11] A. Cachapuz, F. Paixão, J.B. Lopes e C. Guerra, Alexandria, Revista de Educação em Ciência e Tecnologia 1, 27 (2008), disponível em https://periodicos.ufsc br/index.php/alexandria/article/view/37408

[12] G.S. Aikenhead and A.G. Ryan. Science Education 76, 477 (1992), disponível em disponível em http://dx.doi org/10.1002/sce.3730760503.

[13] I.A. Amaral, H. Fracalanza, A.C.R. Amorim e S.M. Serrão, in: Livro Didático de Ciências no Brasil, organizado por H. Fracalanza, J. Megid Neto (Komedi, Campinas, 2006), p. 197-216.

[14] G.S. Aikenhead, Revista Brasileira de Pesquisa em Educação em Ciências 9 (2009), disponível em https://seer.lcc.ufmg.br/index.php/rbpec/ article/view/2204/1604

[15] M.E.V.M. Santos, Revista CTS 2, 137 (2005), disponível em http://www.scielo.org.ar/pdf/cts/v2n6/ v2n6a08.pdf.

[16] J.R. Ledur, Educação para o Trânsito no Ensino de Ciências: Proposta de uma Unidade de Ensino Potencialmente Significativa. Dissertação de Mestrado em Ensino de Ciências e Matemática, Universidade de Caxias do Sul, 2015.

[17] L.L. Silva, Revista Brasileira de Pesquisa em Educação em Ciências 9 (2009), disponível em https://seer.lcc. ufmg.br/index.php/rbpec/article/view/2199/1599.

[18] C.M. De Caro, H.F. Paula, M.B.L. Santos, M.E.C. Castro Lima, N.S. Silva, O. Aguiar Junior, R.S. Castro e S.A.M. Braga, Construindo Consciências - $9^{\circ}$ Ano do Ensino Fundamental (Scipione, São Paulo, 2011).

[19] W.L.P. Santos e E.F. Mortimer, Ensaio - Pesquisa em Educação em Ciências 2, 110 (2000), disponível em http://www.scielo.br/pdf/epec/v2n2/ 1983-2117-epec-2-02-00110.pdf.

[20] I. Martins, in: The Landscape of Scientific Literacy, organized by C. Linder, L. Ostman, D. Roberts, P.O. Wickmann, G.D. Erickson and A. McKinnon (Routledge/Taylor and Francis, New York, 2011), p. 90-105.

[21] E.W. Jenkins, International Journal of Science Education 21, 703 (1999), disponível em http://dx.doi.org/10 1080/095006999290363.

[22] A. Giddens, Modernidade e Identidade (Zahar, Rio de Janeiro, 2002). 